\title{
Mapas callejeros o cómo transitar el área metropolitana de Buenos Aires. La guía Filcar de planos suburbanos de 1955
}

\author{
Street maps: How to circulate in Buenos Aires' Metropolitan Area. Filcar Guide's \\ 1955 suburban maps
}

\author{
Ana Gómez Pintus \\ agomezpintus@gmail.com \\ Instituto de Investigación en Historia, Teoría y Praxis \\ de la Arquitectura y la Ciudad (HiTePAC), Facultad \\ de Arquitectura y Urbanismo de la Universidad \\ Nacional de La Plata - CONICET, Argentina

\section{Florencia Minatta} \\ flor.minatta@gmail.com \\ Instituto de Investigación en Historia, Teoría y Praxis \\ de la Arquitectura y la Ciudad (HiTePAC), Facultad \\ de Arquitectura y Urbanismo de la Universidad \\ Nacional de La Plata- UNSAM, Argentina
}

Recepción: 20 Junio 2020

Aprobación: 14 Julio 2020

Publicación: 02 Noviembre 2020

Cita sugerida: Gómez Pintus, A. y Minatta, F. (2020). Mapas callejeros o cómo transitar el área metropolitana de Buenos Aires. La guía Filcar de planos suburbanos de 1955. Geograficando, 16(2), e082. https:// doi.org/10.24215/2346898Xe082
Resumen: Desde mediados de la década del treinta, acompañando el escenario dinámico de la expansión metropolitana de Buenos Aires se reconoce un notable incremento en la producción de mapas viales, que presentan un panorama muy diverso, en cuanto a los modos de producción y los usuarios a los que pretendían llegar. Sintéticamente, el estudio que aquí planteamos propone el análisis de un caso: la guía Filcar de planos suburbanos de 1955 . Se busca dar cuenta de sus características particulares, formas de producción, de circulación y usuarios a quienes estaba dirigida. Los primeros resultados dan cuenta de que su novedad residía en cubrir un amplio sector del GBA a partir de láminas individuales que presentaban información vial en una escala de entre 1:20.000 y 1:40.000 incluyendo topónimos de calles, con índice lateral y publicidades. Por otro lado, a partir de una metodología de restitución, fue posible dar cuenta de que la guía no recompone la totalidad del área metropolitana, sino que algunos sectores poblados quedan vacantes del relevamiento.

Palabras clave: Gran Buenos Aires, Suburbanización, Cartografía comercial, Siglo XX.

Abstract: From mid-1930s, alongside the dynamic scenario of Buenos Aires' metropolitan expansion, there is a notorious increase in street map publication, with great diversity in production modes and target users. Briefly, this article aims to study the case of Filcar Guide's 1955 suburban map collection. Its peculiar features, production and circulation modes and target users will be discussed. Preliminary results show that its novelty resided in its coverage of a wide Greater Buenos Aires area, in individual sheets presenting road information on a 1:20.000 to $1: 40.000$ scale, including street toponyms, next to a side index and advertisements. On the other hand, with the aid of restitution methodology, it was possible to show that the Guide does not map out the entirety of the metropolitan area: instead, some populated areas are unsurveyed.

Keywords: Greater Buenos Aires, Suburban sprawl, Commercial cartography, Twentieth century. 


\section{INTRODUCCIÓN}

En Argentina, la existencia de mapas, guías comerciales, planos callejeros y planos de caminos debe entenderse por un lado como producto de una renovación en las tecnologías, que posibilitó la reproducción de imágenes en cantidad creciente y con mayor nivel de calidad (Malosetti Costa y Gené, 2013). Al igual que se vincula con la expansión por fuera de los límites de la Capital, justo en el momento en que estos se materializaban a partir de la construcción de la avenida de circunvalación General Paz (1936-1941). Dentro de esta zona, podemos observar en este periodo una tasa de crecimiento anual del Gran Buenos Aires que superaba ampliamente a la de la Capital y la del total del país. Esta brecha se profundizaría hacia los años sesenta, junto al desarrollo del mercado automotriz (Ballent, 2005; Piglia, 2014; Rocchi, 2003).

Los mapas organizaban datos y presentaban información seleccionada, por lo cual, inevitablemente, regulaban los modos de ver y de no ver, de transitar (o no) por las periferias en constante transformación. En este marco se asiste al crecimiento de la producción de mapas, tales como guías, planos callejeros, viales o de servicio, que informan a los viajantes, transeúntes, choferes de remises y colectivos, los recorridos y diversos modos de transitar el Área Metropolitana de Buenos Aires (Favelukes, Gómez Pintus y Novick, 2019).

Llamaremos mapas viales carreteros a aquellos que se concentran en las redes de acceso, caminos, rutas provinciales y nacionales, con una escala intermedia de $1: 100.000 ;{ }^{1}$ los viales callejeros, en cambio, se concentran en las calles en una escala menor de 1:20.000 a 1:30.000, ${ }^{2}$ llevan el topónimo de las calles y su numeración. Por último, los mapas para el turismo concentran información del mapa callejero, en combinación con un mapa de servicios, es decir, un mapa que reúne la información de lugares recomendados para paseo, sitios históricos, museos, y también información útil sobre hospitales y otros servicios. Suelen estar acompañados de publicidades de comercios y otros atractivos locales. ${ }^{3}$

Entre la oferta diversa de este tipo de material proponemos que Filcar encuentra un espacio diferente y novedoso en relación a los usuarios (Rancière, 2008). La guía Filcar no es un mapa -sino que reúne una serie de mapas organizados por localidad, en consecuencia, nunca puede ser desplegado y leído en su totalidad-,su objetivo podría ser dirigir al peatón o automovilista a llegar a una dirección determinada. Lo que despliega en cada una de sus páginas es la escala del barrio--de acuerdo a los límites administrativos de la localidad-, con todas las calles, no importa cuán pequeñas. Este mapa busca, más que la exactitud geométrica o la comprensión general del área metropolitana, dar respuesta a la necesidad de localizar una dirección, o moverse dentro de un área.

De acuerdo a lo expresado, este artículo presenta un primer acercamiento a las fuentes; se plantean objetivos y las principales ideas a modo de hipótesis de trabajo. Queremos profundizar en la operación que significaba la construcción de un producto de tales características (volveremos sobre ello en el cuerpo del texto),el cual, aparentemente, se construye en la combinación de técnicas del callejero y la guía de servicios.

Para verificar estas ideas plateamos las siguientes preguntas: ¿cómo se recopilaba la información?, ¿sobre qué planos trabajaban?, ¿cómo se realizaban los relevamientos? Esto nos permitirá, a su vez, reconocer qué imagen del Gran Buenos Aires se lee a través de Filcar.

\section{Metodología}

En torno al primer punto, proponemos la restitución de las láminas de la guía sobre un plano que seleccionamos como base del área (Carta Topográfica del IGN. Escala 1:1000. 1948).La hipótesis metodológica apunta a que por medio de la reescritura se puede aportar a una mejor comprensión del documento original, renovar la interpretación de sus contenidos e ideas de ciudad con un enfoque crítico en sintonía con los objetivos de la investigación en la cual se aplica (Saavedra Martínez, 2016). Situarse en el lugar del dibujante, cartógrafo que haya concebido el plano original, deducir lo que vieron y las decisiones que 
tomaron nos permitirá dar respuestas a algunas de las preguntas planteadas. En segundo lugar, la restitución completa de las láminas pone a prueba la continuidad espacial de las imágenes, que se construyen desde discursos visuales y no visuales, como la hipótesis-ya discutida por Gómez Pintus (2018)-del tradicional crecimiento en mancha de aceite. ${ }^{4}$ Es posible visualizar la fragmentación del objeto: la guía se fragmenta en láminas sueltas que no llegan a completar el territorio en tanto aparecen espacios o fragmentos intersticiales no cartografiados, es decir, no se trata de un rompecabezas de todo el conurbano, las láminas no se pueden unir entre sí armando un gran mapa de todo el territorio bonaerense. Podemos especular que, para los fines de la guía, solo eran relevantes las áreas pobladas, en tanto que ahí se encontraban los consumidores, usuarios, el resto del área aparecía como intrascendente y consecuentemente no cartografiable. ${ }^{5}$

\section{Resultados y Discusión}

\section{Mapas suburbanos}

Sabemos, entonces, que a partir de los años treinta la acumulación de mapas oficiales, mapas desplegables, guías del callejero, mapas editados para los suplementos de los periódicos y folletos con planos parciales guiaron (o confundieron) a los habitantes del GBA, y, en gran medida, moldearon la naturaleza de la experiencia metropolitana (Favelukes, Gómez Pintus y Novick, 2019).

Con respecto al estudio de los mapas, la literatura hace ya largos años ha puesto en discusión la ilusión de "verdad" o transparencia que ofrecen la fotografía o la cartografía, tradicionalmente percibidas como un registro fiel del objeto que representan (Burke, 2001; Barthes, 1980). Los estudios pioneros de Harley y Woodward (1987) y una prolífica línea de trabajos posteriores pusieron de manifiesto la necesidad de una mirada crítica sobre la cartografía, mostrando la compleja relación que se teje entre mapas, territorios, saberes y culturas. Desde ahí es posible advertir que los mapas a la vez que registran los territorios existentes se convierten en condición de posibilidad para su transformación (Harley, 2005; Lois, 2014; Novick, Favelukes y Vecslir, 2015). En consonancia, y desde lo metodológico, se fue desplazando el foco a los procesos de producción y circulación de los mapas, identificando la formación, el perfil y las competencias de los técnicos que los elaboraron, así como los saberes y las prácticas territoriales que se ponen en juego (Van Damme, 2005; Pousin, 2005).

\section{Filcar, una manera de cartografiar}

La Editorial Filcar fue fundada en la Capital Federal en 1948 y se mantiene en actividad hasta la actualidad, a pesar de los cambios de dueños que se sucedieron a lo largo de los años. Su formación se debería, aparentemente, al interés de sus propios dueños, que fueron los primeros trabajadores de la empresa. Formados en la escuela técnica Otto Krausse, se repartían, personalmente, los trabajos a realizar. El producto que analizamos es la guía Filcar de planos suburbanos publicada por Menéndez y Fiol en 1955. Hasta donde pudo verificarse, la empresa Filcar empezó haciendo guías publicitarias cuyas actualizaciones se realizaban cada dos años y estaban a cargo de grupos de idóneos, técnicos, mediante trabajo de campo y solo lentamente incorporó mapas y guías de caminos, que siguieron combinándose con avisos publicitarios. ${ }^{6}$

\section{La guia: el formato de presentación.}

Los 54 planos suburbanos que componen la guía se presentan en un cuadernillo con anillado metálico, con tapas de cartón, y láminas de cartulina un poco más finas. En la tapa se reconoce el título de "planos 
suburbanos", no se menciona la ciudad de referencia; tampoco contiene sellos institucionales, ni datos de autores, cartógrafos, etc. Solo el signo que marca el norte geográfico aparece acompañando al título (Figura 1).

Fig. 1. Tapa de la publicación

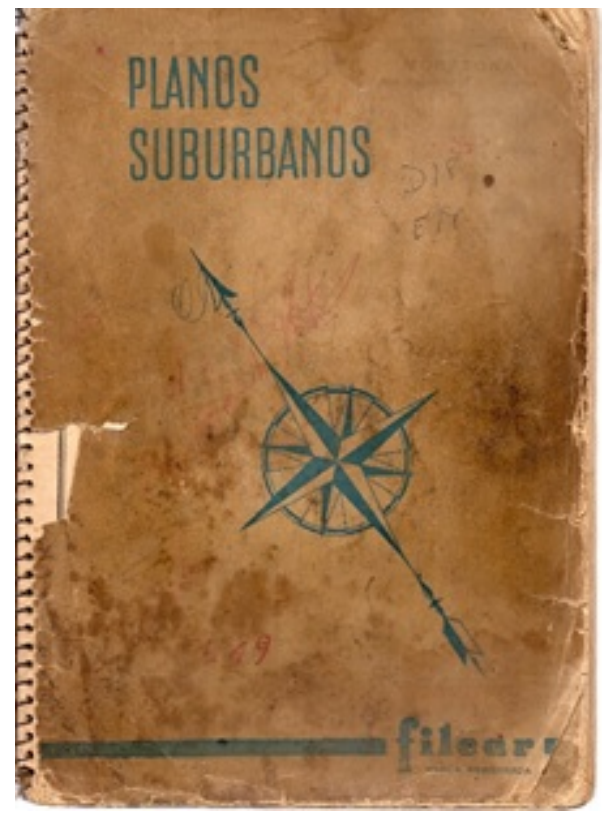

Fuente: Cuadernillo Filcar. Archivo propio

En la primera página la guía contiene la mínima información editorial (año de edición, editorial, precio de venta) y un índice de las localidades que pueden encontrarse. En la tercera página se despliega un plano de las redes ferroviarias suburbanas - con sus respectivas estaciones-,y en la página 5 comienzan los planos que representan los fragmentos viarios por zonas. La información del callejero solo se imprime en las páginas impares, de manera que a página abierta, (par-impar) se lee una página de publicidad -que coincide con la localidad relevada y/o aledaña-,con un índice por calles que refiere al recuadro del gráfico en el que deben buscarse. Por ejemplo, "Gúemes....C-6", y del lado derecho, el plano correspondiente (Figura 2).

Fig. 2. Páginas interiores: página 3 (redes ferroviarias suburbanas); página 6 y 7 (Florida)

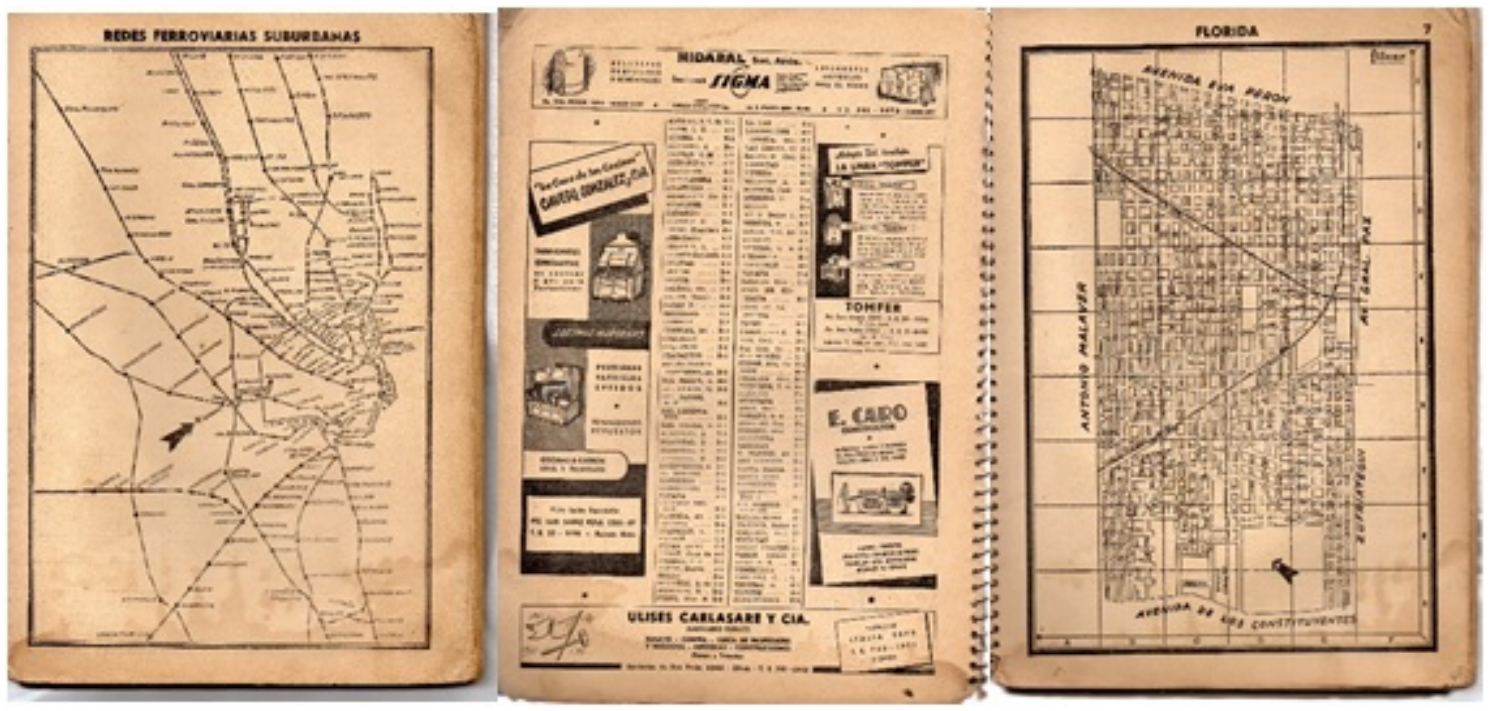

Fuente: Cuadernillo Filcar. Archivo propio 
Las páginas de mapa contienen un recuadro en línea negra de trazo grueso y dentro del mismo se dispone una grilla de doble entrada con letras de la $\mathrm{A}$ a la $\mathrm{F}$ en sentido horizontal, y números del 1 al 9 en sentido vertical. En el centro de la grilla se acomoda el plano del sector con el título ubicado en la parte superior de la hoja. En cuanto a las escalas de representación, la misma no es constante -aunque se reconoce que se inscribe en un arco de 1:30.000 y aporta siempre la misma calidad de datos-, está definida por localidades y por la necesidad de encajar en el recuadro de 17 por $25,5 \mathrm{~cm}$. Por otro lado, si tenemos en cuenta que las páginas se presentan como planos individuales, los datos de la estación funcionan como datos fijos que permiten ubicarse en relación a la totalidad del territorio y al resto de las páginas.

En cuanto a la información que se recolecta en cada lámina, figuran el manzanero, el trazado viario con calles locales, avenidas y rutas, el trazado ferroviario y sus estaciones, y el dibujo de datos de hidrografía (ríos, cuencas, bañados), en todos los casos figuran nombres y topónimos. Respecto a la representación, el trazado y la relación de las vías y manzanas se muestra intencionalmente desproporcionada con respecto a las formas y medidas del objeto que se representa. Asumimos, que con el fin de introducir los números y topónimos, los vacíos de las vías se dibujan más anchos y las manzanas más pequeñas.

En efecto, la valoración que se despliega de las páginas leídas como conjunto, cada página desplegada (Figura 2), permite pensar a Filcar como guía de servicios más callejero a nivel localidad.

\section{La reconstrucción}

a. Para iniciar el procedimiento de restituir cada una de las láminas de Filcar fue colocada sobe el mapa topográfico del Instituto Geográfico Militar (IGM) (sección Campo de Mayo 1:100.000), que fue usado como "mapa base". A partir de ahí fue posible plantear algunos temas.

Se procedió de la siguiente forma: se empezó por tomar una localidad al azar, por ejemplo, Castelar (lámina 49), y se continuó por las láminas consecutivas: 51, Ituzaingó; 53, San Antonio de Padua; 55, Merlo, y 57, Moreno, última estación que incluye la guía. Se volvió sobre las láminas anteriores: 41, Ciudadela; 43, Ramos Mejía; 45, Haedo; 47, Morón, hasta llegar al punto de inicio, Castelar. En principio esto significó escalar "a ojo" cada una de las láminas, de forma tal que coincidieran con el plano base, tomando intencionalmente como "guías" las líneas del ferrocarril, caminos más importantes y cursos de agua. Esto permitió ver que, de acuerdo a los números de las láminas, este tramo va de la lámina 41(Ciudadela) a la 57 (Moreno) y se mueve sobre el eje ferroviario ex Ferrocarril Oeste (Sarmiento), Miserere-Moreno, y se extiende 4 o 5 manzanas hacia adentro de las áreas intersticiales, en las que se registra el trazado y las calles. Dichos tramos se arman sucesivamente alejándose de la Capital hasta aproximadamente el $\mathrm{km} \mathrm{20}$, con centro en la plaza de Congreso (Figura 3). 
Fig. 3. Montaje de las láminas 41 a 57 de Filcar sobre el plano base del IGM, sección Campo de Mayo.

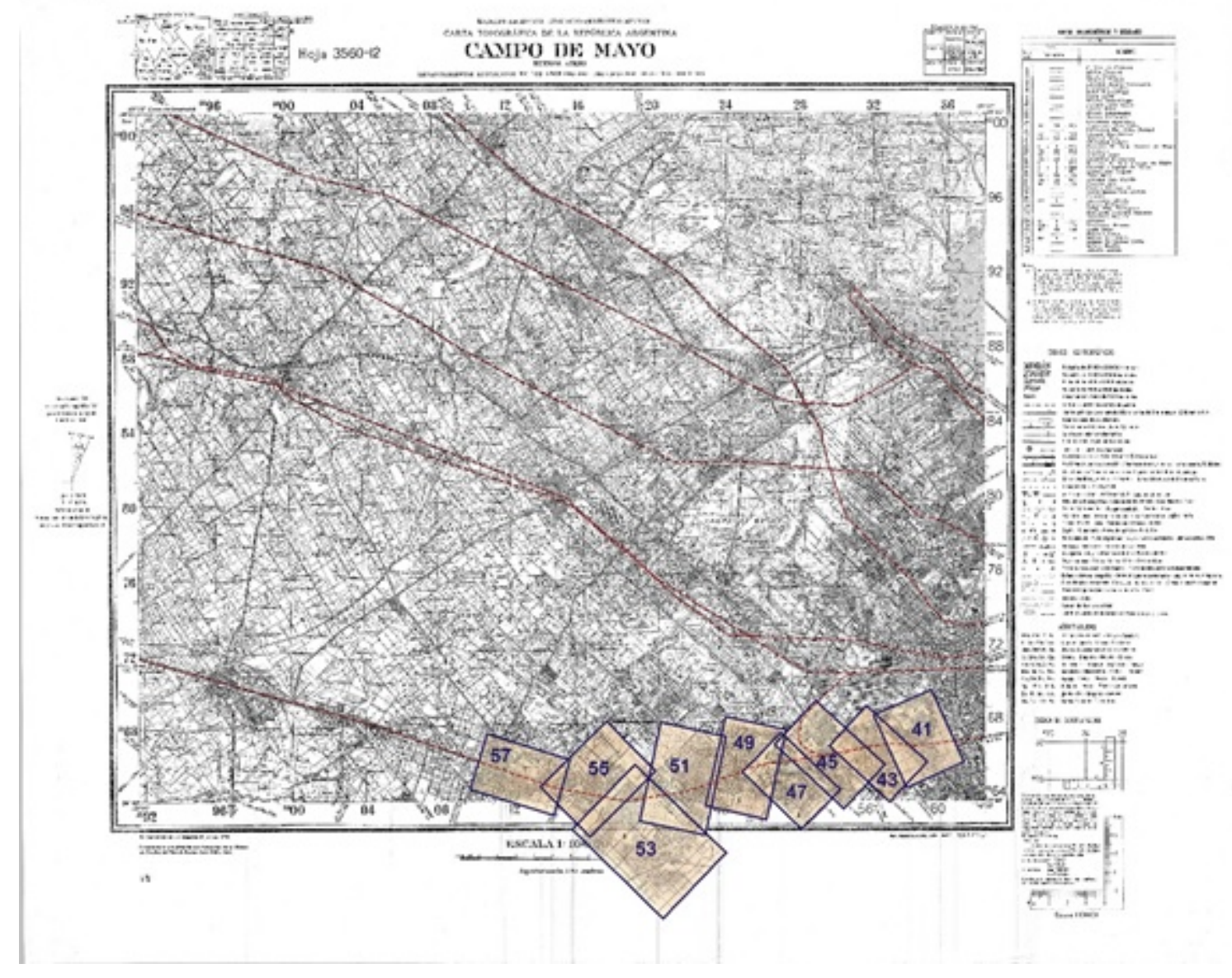

Elaboración: Florencia Minatta.

De acuerdo a lo observado, la lógica de ordenamiento de la guía es tomar, desde el límite con Av. Gral. Paz, la vía primaria o eje del FFCC, que viene desde la Capital y se continúa como eje guía de la expansióninferimos que- hasta el punto o distancia en que la expansión se hace más difusa y el número de usuarios y automovilistas se reduce, de modo tal que ya no sería de interés, ni económicamente rentable seguir con el mapeo del sector. Podemos observar también que el ordenamiento de la guía se corresponde con una lógica radial de las vías del ferrocarril de norte a oeste, y es así como en el plano del IGM "Campo de Mayo" encontramos el Ferrocarril Mitre, ramal Tigre, que comparte láminas con el Ferrocarril Belgrano Norte, ramal Tigre (Láminas 11 a 17); Ferrocarril Belgrano Norte, ramal Villa Rosa (Láminas 19 y 21); Ferrocarril Mitre, ramal Suárez (Láminas 23 y 25); Ferrocarril Mitre, ramal Urquiza y el Ferrocarril San Martín comparten láminas (Láminas 27 a 39), y finalmente el Ferrocarril Sarmiento (Láminas 41 a 57) (Figura 4).

Veamos algunas situaciones particulares detectadas en el caso de la línea San Martín (Palermo- José. C. Paz),la cual transcurre muy cerca de la línea Urquiza (Est. Lacroze-Martín Coronado) y pasa por las estaciones Tropezón, Villa Bosch. Entre estos dos ramales, la restitución sugiere que el recorrido del topógrafo está guiado por la línea más importante (línea San Martín), sobre laque se sigue completando todo el eje (de la lámina 29-Caseros y Santos Lugares; 31 - Palomar; 33 -Hurlingham; 35 -Bella Vista; 37 -San Miguel, hasta la 39-José C. Paz). Luego se completarían aquellas estaciones y áreas adyacentes, por eso Estación Pereyra (línea Urquiza) no tiene mapa propio, porque ya está incluida en la lámina de Hurlingham en el primer eje dibujado (línea San Martín). Mientras que Villa Bosch sí debe ser relevado en una lámina “propia”, que comparte con Ciudad Jardín, El Palomar (lámina 27). Por otro lado, estas láminas "sueltas” se salen del ordenamiento de 
láminas consecutivas que siguen los ejes principales. Si pensamos desde la lógica de armado de esta cartografía, nos gusta llamar a estos ejes como tramos bis. Son ejemplo de estos las láminas 19-21-27 sobre el plano base de Campo de Mayo (Figura 4) y la 67 correspondiente al plano base Ezeiza (Figura 5).

Fig. 4. Montaje de las láminas Filcar sobre el plano base del IGM, sección Campo de Mayo.

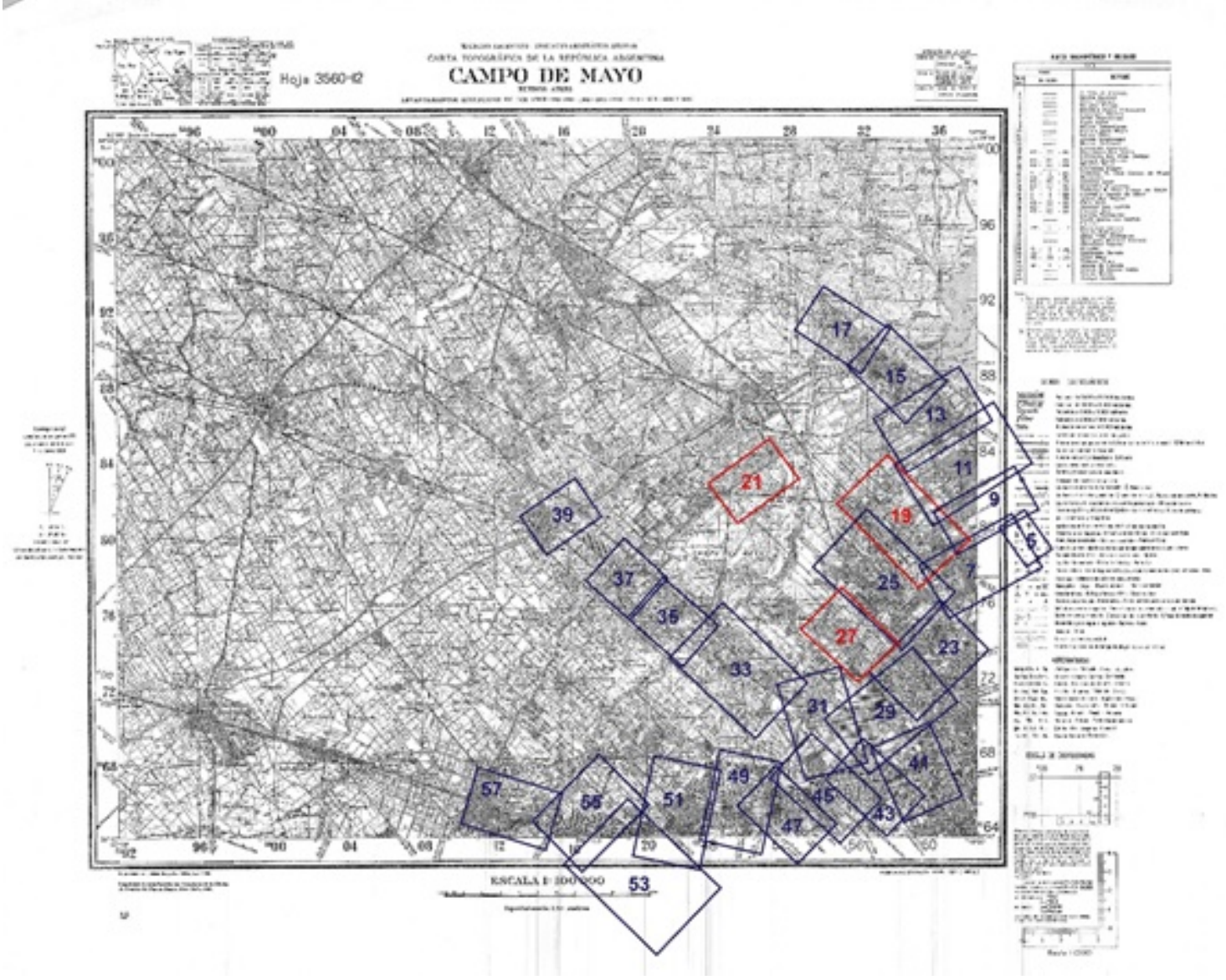

Elaboración: Florencia Minatta. 
Fig. 5. Montaje de las láminas Filcar sobre el plano base del IGM, sección Ezeiza.

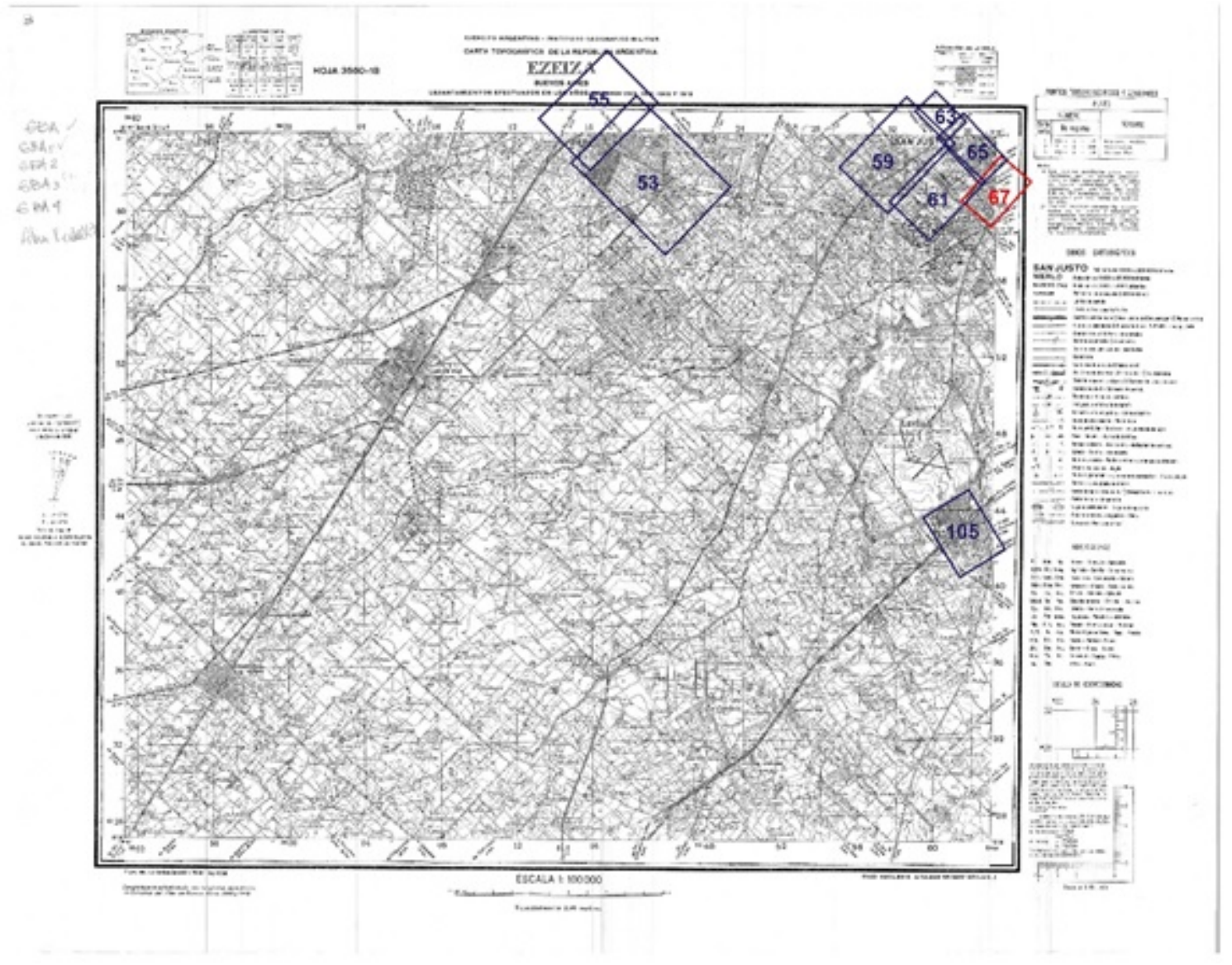

Elaboración: Florencia Minatta.

Es por eso que inferimos que la forma de producción sería: al principio cubrir las áreas, o los ramales que se saben más importantes; una vez terminado ese primer rastrillaje o relevamiento se revisan las estaciones faltantes y se construyen las láminas del resto de las estaciones. De aquí se presentarían dos cuestiones: por un lado, si hacemos un zoom sobre las láminas particulares, tomamos el ejemplo de Ciudadela (Figura 6), el sector compone una forma triangular definida por grandes avenidas de borde, Gral. Paz, avenida Díaz Vélez, avenida República, Marcelo T. de Alvear. La imagen mental que se genera es la de un área recortada sobre un vacío y la consiguiente dificultad de unir el sector con el resto de la trama. Esta misma situación sucede en el plano 23, de San Martín, donde tendría que aparecer Lourdes aparece como sustraído de la traza. Una mirada más aguda al total de las láminas nos deja reconocer que el área "sustraída" del plano 23 aparece "restituida" en el plano 29 de Caseros y Santos Lugares. Presumiblemente, se dibujan localidades, en muchos casos más de una localidad por lámina, siguiendo la premisa de que nunca deben aparecer las localidades cortadas. Esto a su vez podría explicar por qué la mayoría de las láminas -al restituirlas sobre un plano base- tienen un área de trazado que se superpone con su consecutiva (Figura 7), mientras que en los ejemplos mencionados se decide dejar vacante el dibujo en un sector (lámina) y reaparecer en otro sector, de modo que hay una decisión de no superponer lo que se dibuja en uno u otro plano. 
Fig. 6. Láminas Filcar y detalle de montaje sobre un sector Ciudadela, sobre el plano del IGM, sección Campo de Mayo

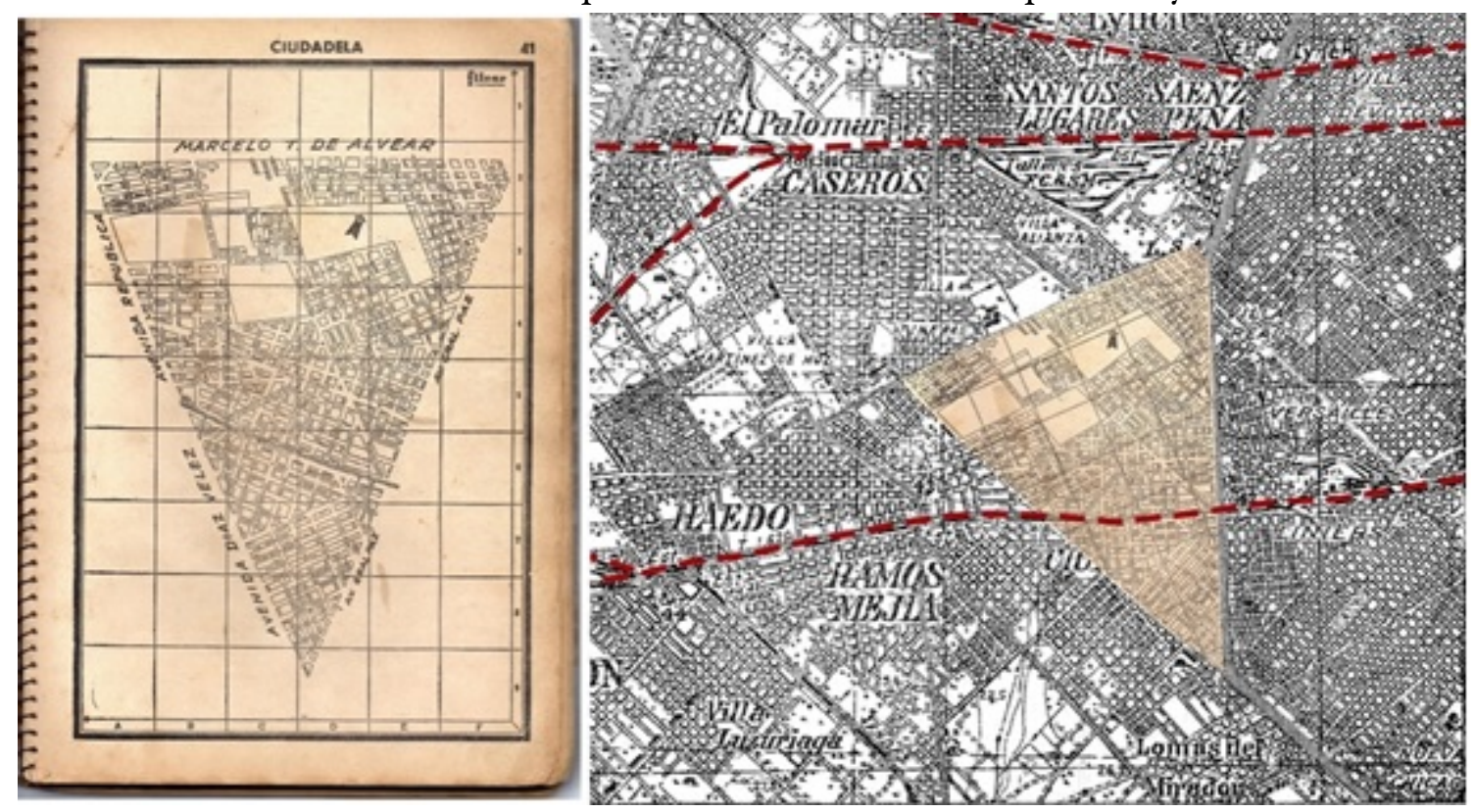

Elaboración: Florencia Minatta.

Fig. 7. Láminas Filcar y detalle de montaje sobre un sector San Martín y Caseros, sobre el plano base del IGM, sección Campo de Mayo

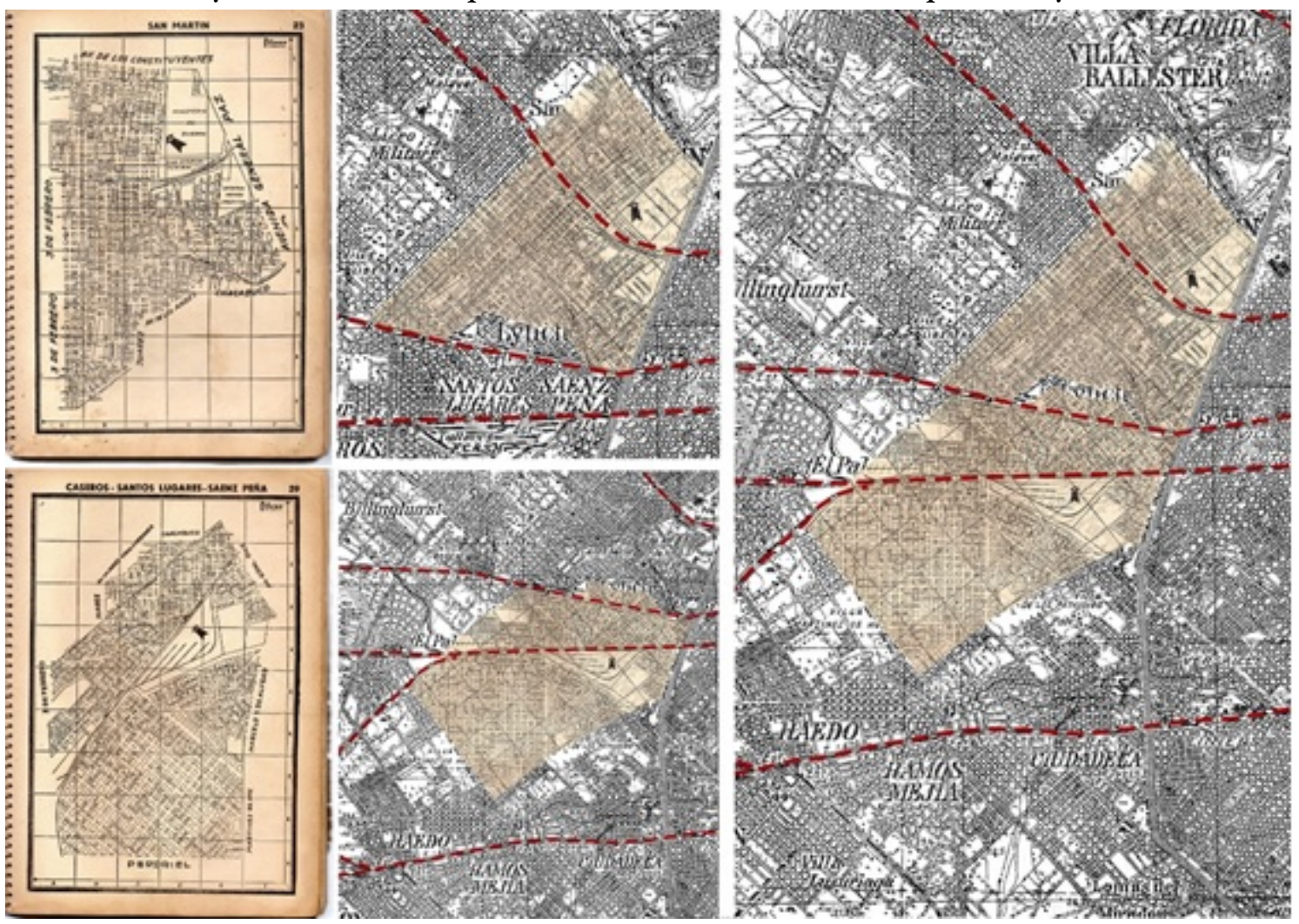

Elaboración: Florencia Minatta. 
b. Por otra parte, esta metodología nos permitió visualizar las láminas para dar cuenta de que los límites de la Ciudad Autónoma de Buenos Aires nunca fueron cartografiados, sino que se relevaron solo aquellos sectores donde se encuentran presentes vías del ferrocarril y caminos principales de acceso a la ciudad. Más importante, el trabajo nos permite reconocer una serie de espacios intermedios que van quedando vacantes (sin cobertura), sin mapa.

Al igual que en la introducción, donde se planteó la idea de situarse en la posición del cartógrafo para poder pensar en primera persona el acto de cartografiar, proponemos ahora situar nuestra atención en el rol del automovilista que se mueve por el territorio definido por la guía. ${ }^{7}$

La escena sería la siguiente: un automóvil se traslada siguiendo las nuevas rutas que se extienden por las áreas intermedias que a fines del siglo XIX había dejado el FFCC vinculando los ejes radiales; de repente, tiene que parar.

Nosotros, que vemos la restitución cartográfica sabemos que lograr la continuidad de la trama vial interurbana usando la Filcar es un intento casi imposible. Por un lado, algunas de estas áreas -como puede verse en la lámina de Campo de Mayo (Figura 4) - quedan sin la cobertura, de manera que por momentos el usuario (automovilista o peatón) se quedaría sin mapa, y tendría que atravesar un vacío cartográfico. Incluso cuando las áreas intersticiales quedan cubiertas, por la proximidad de las vías radiales, serían casi imposibles de seguir dado que no forman parte de láminas consecutivas en la guía (la situación sería la del automovilista que "cae del mapa" y busca desesperadamente la página que lo vuelva a incluir en un área relevada).Si imaginamos que este automovilista quiere ir desde Hurlingham a Beccar, debe tomar el Camino de Cintura en su tramo norte, debería "trasladarse" por las páginas 33, 27, 25, 19 y 13 atravesando el vacío que queda entre la 33 y la 27. Como se lee en el plano (Figura 8), sería imposible realizar este mismo recorrido tomando un radio más amplio, más alejado de la Av. Gral. Paz.

En efecto, además de la fragmentación de la guía, esta pequeña narración deja en evidencia las posibilidades de la restitución de la misma, al iluminar situaciones que solo quedan a la vista en el plano de conjunto. 
Fig. 8. Montaje completo sobre plano del IGM, sección Campo de Mayo.

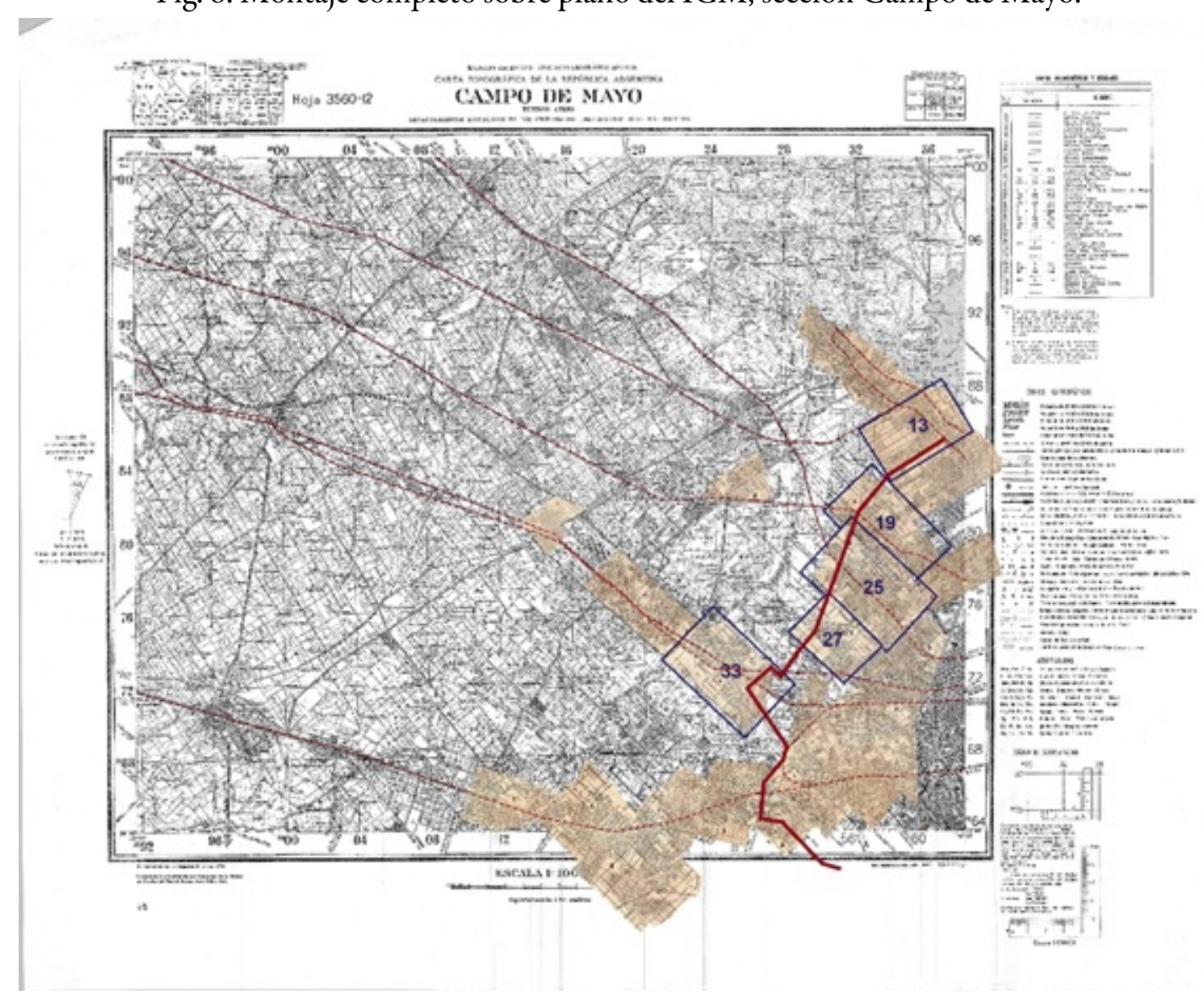

Elaboración: Florencia Minatta.

Situaciones similares se reconocen sobre el área registrada sobre el plano base denominado "Ezeiza", donde se pudieron continuar los ramales correspondientes a las láminas situadas en planos base anteriores: Ferrocarril Belgrano Sur (láminas 53 -compartida con el Ferrocarril Sarmiento- y 67); Ferrocarril Roca, ramal Haedo (láminas 59, 61 y 65); y Ferrocarril Roca, ramal Ezeiza (lámina 105) (Figura 9).

Interesante fue notar que, a diferencia del resto de las láminas restituidas, la lámina 65 -Villa InsuperableVilla Scasso- no cuenta con vías ferroviarias relevadas, aunque se verifica claramente en el plano base que por allí atraviesa el Ramal Haedo del Ferrocarril Roca. La lámina 63 -Lomas del Mirador- muestra una ausencia de vías ferroviarias, sin embargo fue relevada, creemos, por su cercanía a la Av. General Paz (Figura 10). 
Fig. 9. Montaje de las láminas Filcar sobre el plano base del IGM, sección Ezeiza.

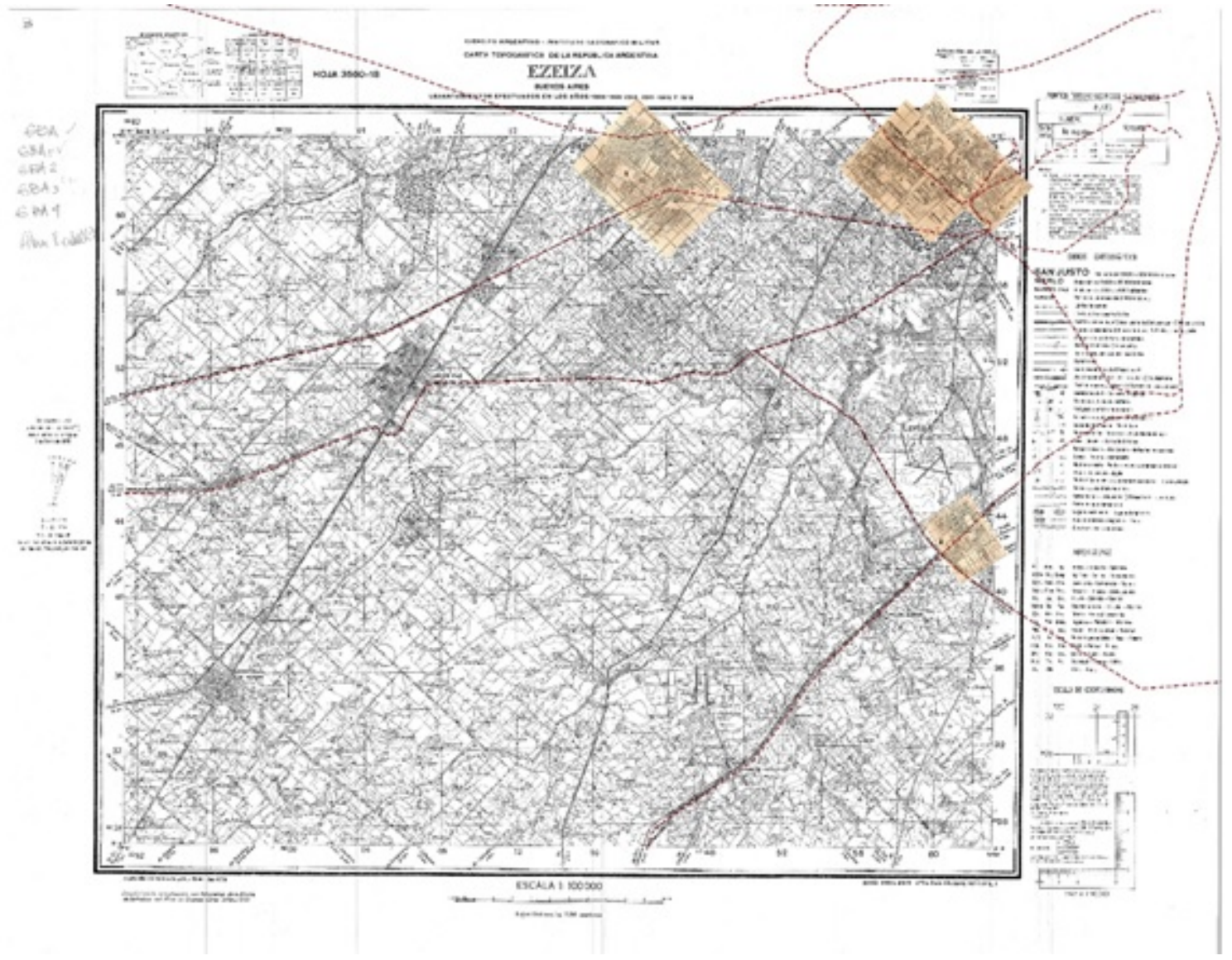

Elaboración: Florencia Minatta.

Fig. 10. Particularidad de las láminas 63 y 65 en el plano base del IGM, sección Ezeiza.

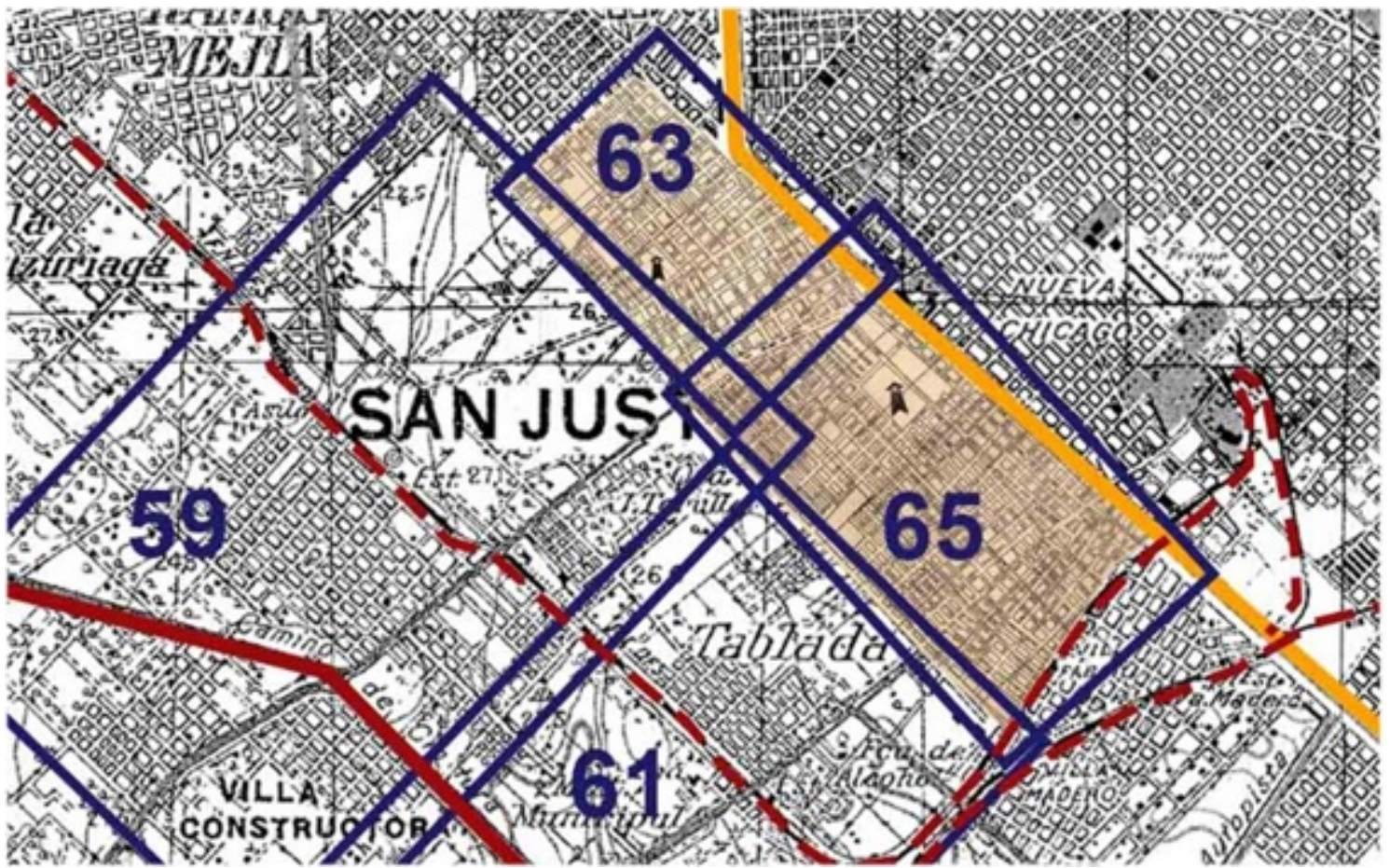

Elaboración: Florencia Minatta 
Finalmente se terminó de completar con los planos de Avellaneda y Capital (Figuras 11 y 12).

Fig. 11. Montaje de las láminas Filcar sobre el plano base del IGM, sección Avellaneda.

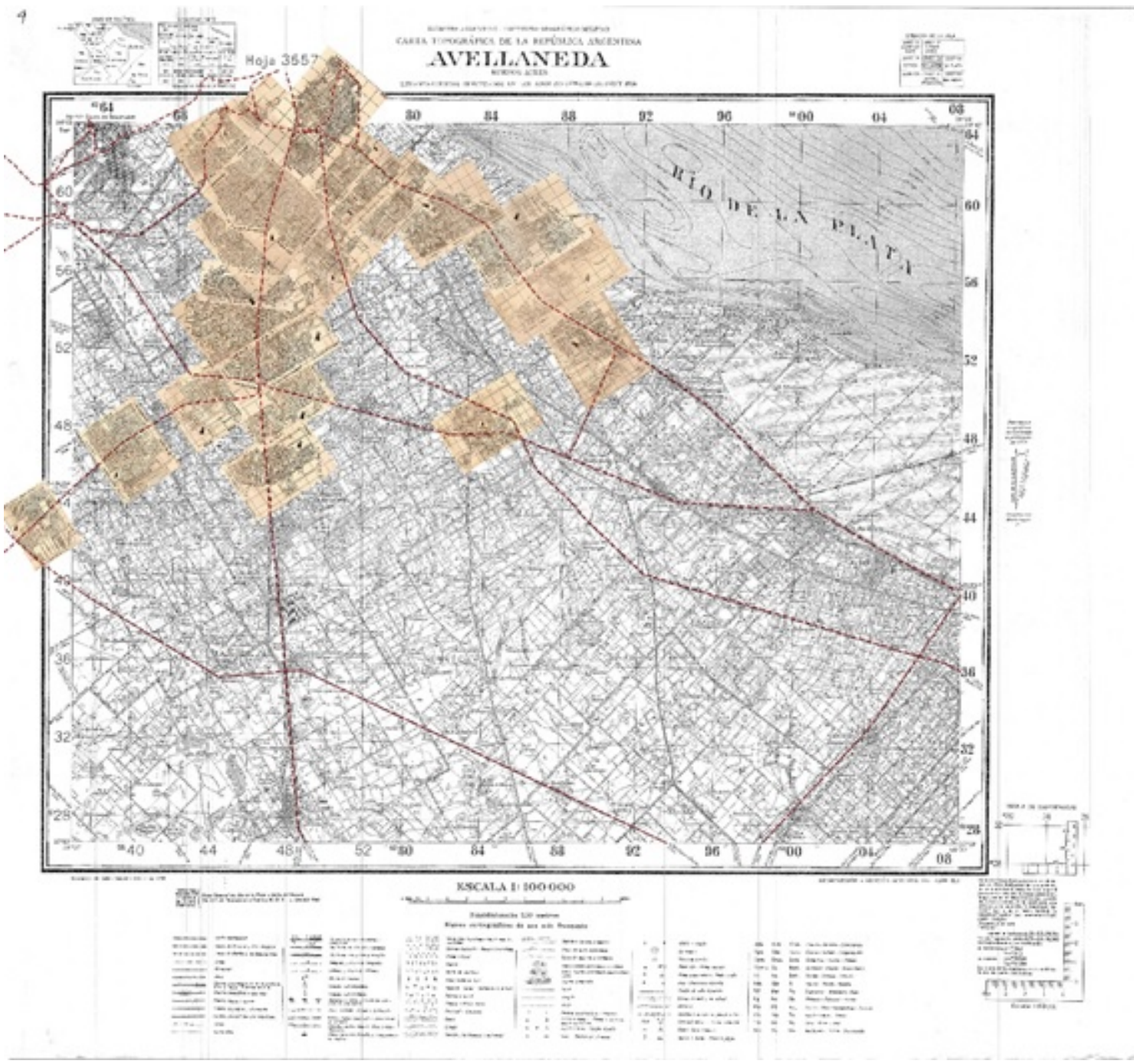

Elaboración: Florencia Minatta. 
Fig. 12. Montaje de las láminas Filcar sobre el plano base del IGM, sección Capital.

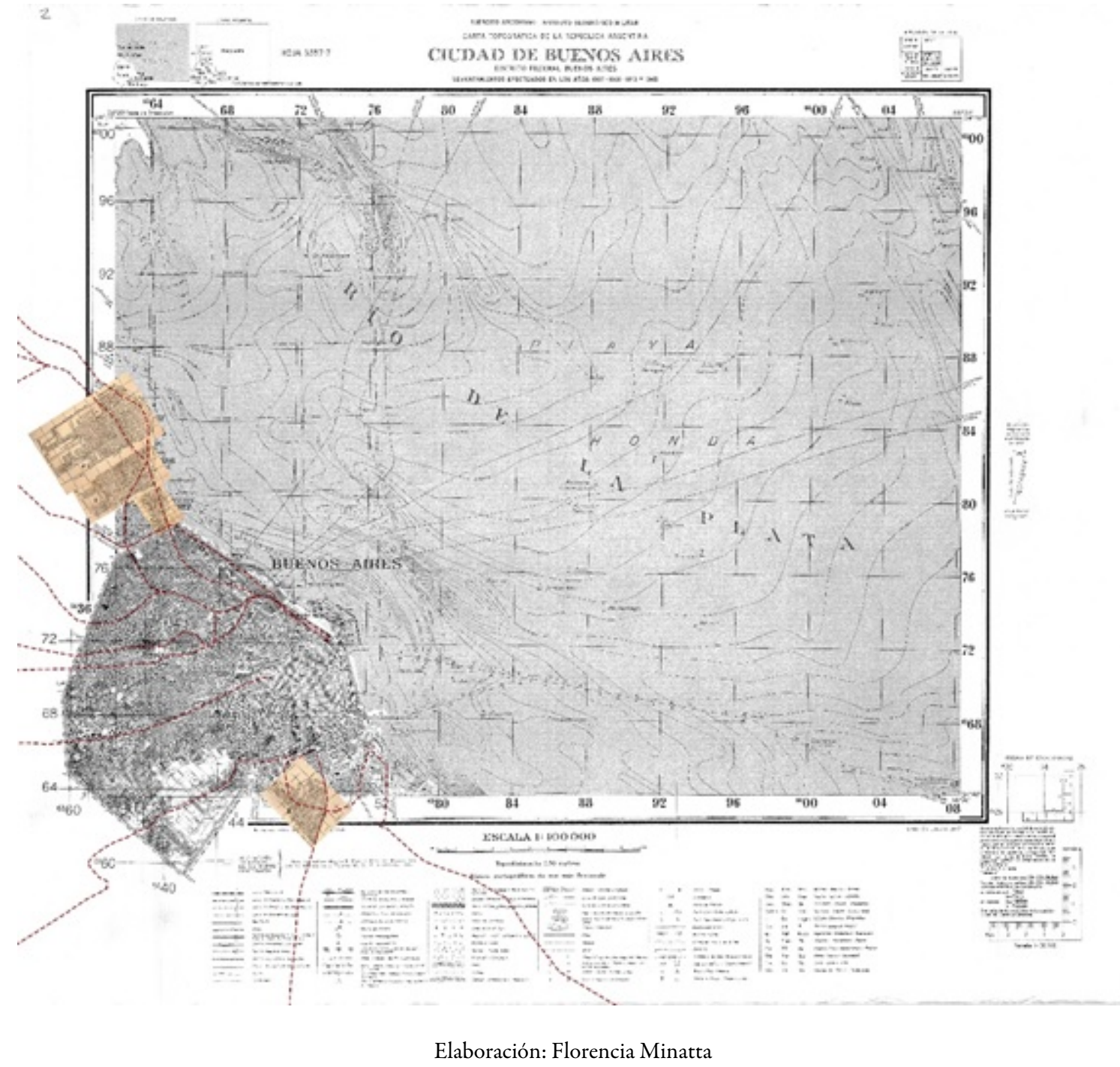

Si observamos el resultado final, no existe la grilla como idea totalizadora, sino una serie de láminas que se arman siguiendo la lógica de quienes recorrían el campo (Favelukes, 2013; Mazzitelli, 2017),y de lo que se presume era "atractivo" para sus consumidores. Así procedían desde la capital hacia las "afueras", con una libertad en relación a las diferentes láminas, las cuales se acomodaban en el taller tratando de aprovechar al máximo el papel. Aunque en este caso lo que surge a primera vista y se verifica una vez realizada la restitución cartográfica general es la idea de que el mapa es imposible de completar (Figura 13). 
Fig. 13. Restitución completa de las láminas que componen la guía Filcar sobre el plano base del IGM.

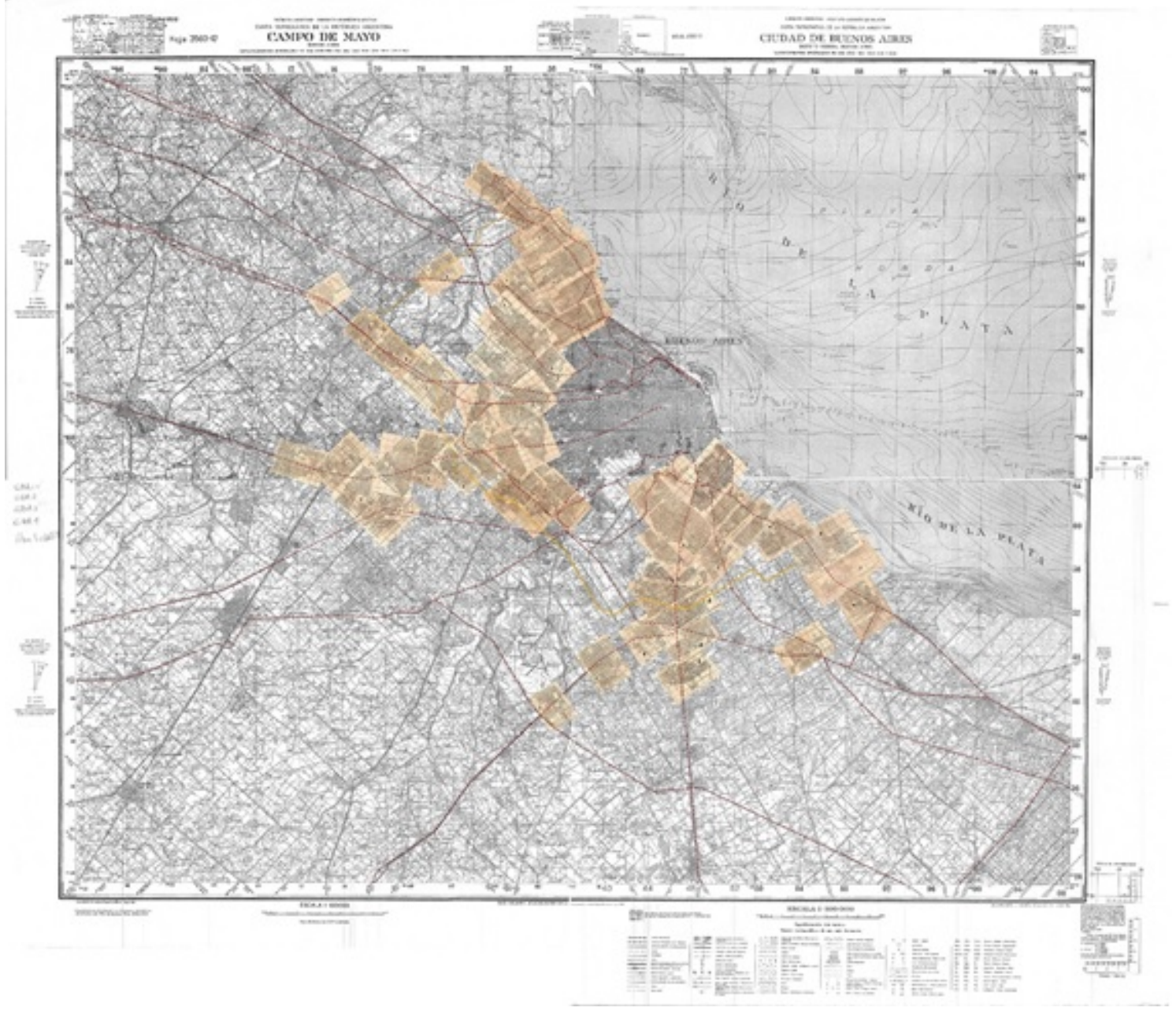

Elaboración: Florencia Minatta

\section{Conclusiones}

A través de esta investigación se buscó dar cuenta las características particulares de la guía Filcar: formas de producción, de circulación y usuarios a quienes estaba dirigida. A la vez, se buscó evidenciar la imagen del GBA que se reconocía a través de Filcar. ¿Qué podía decir este mapa del GBA?

Metodológicamente, se planteó como uno de los objetivos de esta investigación restituir el territorio que dibuja Filcar a partir de los fragmentos que se presentan en la guía. Se trabajaron todos los sectores de los planos utilizados como base, y se unieron las cuatro hojas para conformar el plano total correspondiente a la restitución del territorio de la guía Filcar (Figura 13).

Así, desde esta mirada, podemos señalar la productividad de la restitución, en tanto que nos permitió reconocer aportes a los que hubiera sido imposible llegar analizando solo láminas individuales, tal como se presentaban en su formato de venta. A su vez, este análisis nos permitió organizar ciertas conclusiones:

En cuanto al armado, se demostró que en el caso de Filcar nunca existió un territorio grillado, de modo que la guía se iba construyendo a medida que las vías se extendían, y su continuidad en el plano dependía de las decisiones individuales de los cartógrafos o de lo que asumieran podían ser los intereses de los futuros compradores. En este sentido, puede pensarse (al menos en los orígenes) en un producto artesanal, casi familiar. 
De lo mencionado se desprende que no se trabajaba sobre la idea, el concepto de una imagen completa del GBA, desde el proyecto inicial de la empresa. Creemos que no existió nunca la intención de completar el plano; no estuvo entre los objetivos del propio mapa. Los relatos sobre el automovilista que "se cae" del mapa cuando se termina la página por la que "transita” y no sabe cómo seguir, o la imagen de caer en un vacío cartográfico abonan esta hipótesis en tanto vemos que Filcar no mejora la comunicación general dentro del GBA, ni visibiliza las conexiones en forma de red que unían puntos importantes.

Lo que la restitución consigue-por fuera de la propia guía- es refutar una serie de hipótesis más amplias sobre el GBA, como son las del crecimiento homogéneo en mancha de aceite.

En relación al análisis de los usos posibles, la circulación y los posibles usuarios, debemos remitir al análisis de sus páginas, no solo del callejero sino de la página completa (par-impar).Resulta verosímil pensar que los encargados de la construcción de Filcar buscaban ofrecer datos claros a los recientes automovilistas. Si los primeros mapas desplegables ofrecían una primera aproximación a la expansión, destinados a quienes atravesaban el área, brindando información general sobre un sector que comenzaba a hacerse visible para los porteños como paseo turístico (plano Ludwig de los alrededores de la Capital Federal 1928 con indicación de los caminos para el turismo publicado por la oficina cartográfica Ludwig [Alsina 1146. Escala 1:125.000]; y plano de los caminos principales y los ferrocarriles de los alrededores de Buenos Aires publicado por el diario La Prensa), las guías con láminas página por página atendían a otro tipo de usuario, que es el habitante suburbano. Pensemos en los remiseros, o viajantes de comercio, que quizá abrían la página en Merlo y hacían múltiples recorridos siempre dentro de determinada zona, o los transeúntes y vecinos de un área en trasformación, que requerían la información del recorrido detallado puerta a puerta.

En líneas generales podemos concluir que la guía Filcar se construye en la combinación de ambas lógicas: la del mapa callejero suburbano, que funciona en la unificación de las láminas, y la de la guía de servicios, cuando se atiende a la página desplegada en la escala barrial.

Es en esta línea que a Filcar no le preocupa la totalidad del territorio. Su carácter único diferencial podría estar en el uso de información que aporta al interior de las propias localidades. En el relevamiento de áreas pobladas y con algún tipo de accesibilidad, como ya se adelantó, el resto del área aparecía como intrascendente y consecuentemente no cartografiable.

\section{Agradecimientos}

Ese trabajo es posible gracias al CONICET y al proyecto sobre Periferias Metropolianas (U 178) del HiTePAC, Facultad de Arquitectura y Urbanismo, Universidad Nacional de La Plata. En el ámbito personal queremos agradecer a la Dra. Graciela Favelukes y al grupo de estudios que dirige en el Instituto de Arte Americano, IAA, UBA, por contribuir a las primeras ideas sobre las que luego fue creciendo el trabajo.

\section{REFERENCIAS}

Ballent, A. (2005). Kilómetro cero: la construcción del universo simbólico del camino en la argentina de los años treinta. Boletin del Instituto de Historia Argentina y Americana Dr. Emilio Ravignani, 27, 107-137. Recuperado de http://www.redalyc.org/articulo.oa?id=379444921004

Ballent, A., y Gorelik, A. (2001). País urbano o país rural: la modernización territorial y su crisis. En A. Cattaruzza (Dir.), Nueva Historia Argentina. Tomo VII. Crisis Económica, avance del Estado e Incertidumbre Política (pp. 143-200). Buenos Aires: Editorial Sudamericana.

Barthes, R. (1980). La cámara lucida. Notas sobre fotografía. Buenos Aires: Editorial Paidós.

Burke, P. (2001). Visto y no Visto. El uso de la imagen como documento histórico. Barcelona: Editorial Crítica. 
Caride, H. (1994). Un poco antes del horizonte. Estructura Administrativa de la campaña de Buenos Aires en el Siglo VIII. Crítica, Instituto de Arte Americano e Investigaciones Estéticas "Mario J. Buschiazzo", 52, 2-22. Recuperado de http://www.iaa.fadu.uba.ar/publicaciones/critica/0052.pdf

Favelukes, G. (2013). Notas para una historia territorial: los mapas catastrales de Carlos de Chapeaurouge. Critica, Instituto de Arte Americano e Investigaciones Estéticas "Mario J. Buschiazzo", 187, 2-12. Recuperado de http://w ww.iaa.fadu.uba.ar/publicaciones/critica/0187.pdf

Favelukes, G., Gómez Pintus, A., y Novick, A. (2019). Figuraciones del suburbio. Mapas comerciales y expansión metropolitana en el Gran Buenos Aires. 1940-1950. EGA. Expresión Gráfica Arquitectónica, Universidad Politécnica de Valencia, 24, 156-167. Doi: 10.4995/ega.2019.10952.

Gómez Pintus, A. (2018). Las formas de la expansion 1910-1950. Barrios Parque y loteos de fin de semana en la construcción del espacio metropolitano de Buenos Aires. Buenos Aires: AEFAU +Diseño.

Harley, J. (2005). La nueva naturaleza de los mapas. Ensayos sobre la historia de la cartografía. México: Fondo de Cultura Económica.

Harley, J. y Woodward, D. (Eds.) (1987) The history of cartography, vol. 1: Cartography in prehistoric, ancient, and medieval Europe and the Mediterranean. Chicago: University of Chicago Press.

Lois, C. (2014). Mapas para la Nación. Episodios en la Historia de la Cartografía en Argentina. Buenos Aires: Editorial Biblos.

Malosetti Costa, L., y Gené, M. (Comp.) (2013). Atrapadospor la imagen. Arte y política en la cultura impresa argentina. Buenos Aires: Edhasa.

Mazzitelli, M. (2017). Paisajes montados. El uso de las vistas, bosquejos, notas, fotografias y otros insumos visuales para la traducción de información topográfica de la Dirección Nacional de Minas, Geología e Hidrología (Tesis de doctorado) Facultad de Filosofía y Letras, Universidad de Buenos Aires, CABA, Argentina.

Novick, A.; Favelukes, G., y Vecslir, L. (2015). Mapas, planes y esquemas en la construcción del Gran Buenos Aires. Revista Anales del Instituto de Arte Americano e Investigaciones Estéticas "Mario J. Buschiazzo", 45, 55-72. Recuperado de: http://www.iaa.fadu.uba.ar/ojs/index.php/anales/article/view/162

Piglia, M. (2014). Autos, rutas y turismo. El automóvil club argentino y el estado. Buenos Aires: Siglo XXI.

Pousin, F. (2005). Figure de la ville et construction des savoirs. Architecture, urbanisme, géographie. Paris: CNRS Editions. Available at: http://books.openedition.org/editionscnrs/4267

Rancière, J. (2008). El espectador emancipado. Buenos Aires: ediciones Manantial.

Rocchi, F. (2003). La americanización del consumo: las batallas por el mercado argentino, 1920-1945. En A. Regalsky y M. Barbero, Americanización Estados Unidos y América Latina en el siglo XX, transferencias económicas, tecnológicas y culturales (pp. 131-190). Buenos Aires: Universidad Nacional de Tres de Febrero.

Saavedra Martínez, C. (2016). Investigar desde la transcripción: redibujar y reescribir el "Plano Oficial de Urbanización de la Comuna de Santiago" de 1939. Estudios Del Hábitat, 14(2), pp. 1-15. Recuperado de https://revistas.un lp.edu.ar/Habitat/article/view/e008

Szir, S. (2013). Arte e industria en la cultura gráfica porteña: la revista Éxito gráfico (1905-1915). En L. Malosetti Costa y M. Gené, (Comps.), Atrapados por la imagen. Arte y politica en la cultura impresa argentina (pp. 165-189). Buenos Aires: Edhasa.

Van Damme, S. (2005). Les sciences humaines à l'épreuve de la ville: les enjeux d'une archéologie des savoirs urbains (XVIIe-XXe siècles). Revue d'Histoire des Sciences Humaines, 1(12), 3-15. Available at http://www.cairn.info/ article.php?ID_ARTICLE=RHSH_012_0003

\section{Notas}

1 Por ejemplo, el mapa Ludwig caminos de acceso 1:125.000. 1927.

2 Por ejemplo, el Novísimo. Plano Moderno de Buenos Aires. Joseph Ritter. 1905. Escala: 1:31.500.

3 Guía Peuser de los alrededores de Buenos Aires y principales rutas nacionales y circuitos de turismo. 1950. Plano plegable que se entrega con la Guía de Turismo Peuser. 1950 
4 La hipótesis del crecimiento en mancha de aceite fue expuesta por la CONADE en 1969 e implicaba la idea la expansión con crecimiento en forma de "mancha de aceite", sin ejes establecidos ni lineamientos que seguir. Horacio Caride (1994) expuso una idea contraria al proponer que la estructura espacial de lo que posteriormente se llamaría el GBA se fue consolidando a partir de las preexistencias: caminos, capillas, puertos, guardias y fortines, que, con distintos grados de relación, estuvieron vinculados con los primeros asentamientos urbanos del área, los cuales serían fundamentales para guiar su desarrollo posterior. En el libro Las formas de la expansión 1910 - 1950, Gomez Pintus se retoma esta discusión para mostrar cómo la expansión relacionada con los barrios de fin de semana o barrios parques tuvo diferentes estrategias de localización, que priorizaban, en algunos ejes, la cercanía a la estación, mientras que otros casos eligieron adentrarse un poco sobre las áreas intermedias que dejaba la urbanización, a fin de conseguir tierra más barata y lotes más amplios. Lo que esto demuestra es que la expansión se realizó por fragmentos, cubriendo el territorio por áreas, lo que generó un patchwork que para los años cincuenta se veía bien diferente al del crecimiento homogéneo en mancha de aceite.

5 Con esto queremos decir que no formaba parte de los objetivos del propio mapa.

6 Entrevista realizada en la compañía Filcar (2018).

7 Estos párrafos se plantean como un ejercicio que recrea situaciones posibles en el contexto del uso de la guía. Sin desconocer la discusión que entre otros plantea Jacques Rancière (2008) sobre un espectador, lector “emancipado" que no "recibe" ingenuamente la información brindada sino que tiene la capacidad de seleccionar, elegir, completar posibles vacíos a partir de conocimientos o recuerdos propios, hemos decidido dejar de lado esta discusión para otra ocasión, y profundizar aquí aquellos temas que más directamente responden a los objetivos del trabajo. Investigar sobre las formas de producción de la guía y por la imagen que despliega del Área Metropolitana. 